\title{
Anatomy of the Middle Cerebral Artery: Cortical Branches, Branching Pattern and Anomalies
}

\author{
Karen CILLIERS, Benedict John PAGE \\ Stellenbosch University, Department of Anatomy and Histology, Cape Town, South Africa
}

\section{ABSTRACT}

The middle cerebral artery (MCA) covers a large part of the cerebral hemispheres and is therefore exposed during surgical intervention in this area. Aspects of cerebral branches tend to vary, different branching patterns can be described, and several anomalies can be observed. Knowledge of these variations and anomalies is important and can be helpful to neurosurgeons and clinicians. The aim of this manuscript was to review the available literature on the cortical branches, branching pattern and anomalies of the MCA, to identify the gaps in the literature, and to fill these gaps by including the results of a pilot study.

Twenty hemispheres were perfused with colored silicone and the MCA was dissected. For the cortical branches, the diameter, length, presence, duplication and origins were noted. Most commonly duplicated was the anterior parietal artery in $30.0 \%$, and most commonly absent was the common temporal artery in $65.0 \%$. A detailed description on the origins is given. Criteria were described for the bifurcation subtypes and medial bifurcation (50.0\%) was most commonly observed. No anomalies were observed.

Aspects previously neglected of the MCA cortical branches were reported in the pilot study. The branching subtypes were identified and criteria are given. Illustrations of the different branching subtypes and anomalies are provided. Certain aspects of the MCA anatomy have been neglected, and future studies should give adequate descriptions of the MCA cortical branches, MCA branching pattern, and any anomalies observed.

KEYWORDS: Anomaly, Bifurcation, Branching, Cortical branch, Middle cerebral artery, Trifurcation, Variation

\section{INTRODUCTION}

$\mathrm{T}$ The middle cerebral artery (MCA) covers a large part of the cerebral hemispheres and is exposed during surgical intervention in this area $(17,63)$. Aspects of cerebral branches tend to vary, different branching patterns can be described, and several anomalies can be observed. Knowledge of these variations and anomalies is important and can be helpful to neurosurgeons and clinicians (20). The diameter, length, absence and duplication of the MCA cortical branches are not thoroughly reported. Furthermore, descriptions of the origins and possible common trunks of these branches are still lacking in the literature. Bifurcation and trifurcation branching types are usually described, while most studies fail to mention the different subtypes. Moreover, there is still some confusion on the criteria of these different subtypes. The MCA anomalies are often mentioned in the literature, although the subtypes are rarely elaborated on. Therefore, the aim of this study was to firstly review the available literature on the cortical branches, branching pattern and anomalies of the MCA, secondly to identify the gaps in the literature, and lastly to fill these gaps by including the results of a pilot study.

\section{REVIEW}

This review will include a discussion on the cortical branches, on the branching pattern and on the possible anomalies, since these aspects can vary tremendously. The cortical branches typically arise from the main MCA trunk, which can be divided 
into four segments; the M1 segment (sphenoid or horizontal segment), the M2 segment (insular segment), the M3 segment (opercular segment), and the M4 segment (cortical branches). The branching of the MCA involves the trunk (M1 or M2 segment) of the MCA dividing into two or three smaller trunks. Anomalies can be observed at the first part of the MCA trunk, which includes extra vessels and fenestration $(5,39,56,63)$. The cortical branches, the branching pattern, and the possible anomalies of the MCA will be discussed separately.

\section{Cortical Branches}

The cortical branches include the orbitofrontal artery (OfA), prefrontal artery (PfA), precentral artery (PcA), central artery (CA), anterior and posterior parietal arteries, angular artery (AA), temporal arteries (temporopolar, anterior, middle and posterior temporal arteries) and temporo-occipital artery (ToA). These cortical arteries can arise prior to the branching, from the trunks formed by the branching, from another cortical branch or in conjunction with another cortical branch (56). The most common origins of these cortical arteries are illustrated in Figure 1.

Origin prior to branching: If a cortical artery originates prior to the initial branching, the artery is referred to as an "early branch". Early branches can be divided into early frontal branches (EFB) or early temporal branches (ETB) $(7,17,23,55,63,71)$. The OfA, temporopolar artery and anterior temporal artery (ATA) typically arise as early branches $(17,63)$. Four configuration can be defined; no early branches, only EFB, only ETB, or early frontal and early temporal branches (75). Rhoton (63) stated that there is typically only one early branch present, while Ciszek et al. (7) stated that an EFB was frequently positioned between two ETB. Gibo et al. (17) observed five cases (10.0\%) of EFB and 17 cases $(34.0 \%)$ of early temporal branches. Furthermore, Ogeng'o et al. (55) observed 104 cases (36.1\%) of EFB and 184 cases (63.9\%) of early temporal branches.

Origin after branching: When the cortical branch arises after the branching, it can originate from the superior, middle or inferior trunk. In bifurcation and trifurcation (Figure 1), the inferior trunk usually gives rise to the temporal arteries. The parietal arteries and the angular artery can arise from either trunk in bifurcation, and usually arises from the middle trunk in trifurcation. If bifurcation occurs, the superior trunk typically gives rise to the OfA, prefrontal, precentral and central arteries. With the trifurcation pattern, the superior trunk usually gives rise to the OfA and prefrontal arteries, while the precentral and central arteries can originate from either the superior or the middle trunk $(5,39,47,63,72,84)$.

\section{Branching Pattern}

The branching pattern is determined by the division of the main trunk into smaller trunks. Bifurcation and trifurcation is most commonly described, although other types have been observed and several subtypes can be identified. Eleven different branching types can be distinguished from the literature and these include bifurcation subtypes (medial bifurcation, lateral bifurcation, medial pseudobifurcation, and lateral pseudobifurcation), trifurcation subtypes (true trifurcation, pseudotrifurcation, proximal trifurcation, and distal trifurcation), monofurcation, tetrafurcation, and pseudotetrafurcation (Figure 2A-K) $(5,19,39,56)$.

Bifurcation subtypes: For the bifurcation subtypes, medial and lateral branching refers to the distance of the branching from the MCA origin (either close or further away, respectively). In pseudobifurcation (also referred to as false bifurcation), a large cortical artery originates from the main trunk and gives a false impression of a bifurcation (39).

Trifurcation subtypes: In the trifurcation subtypes, true trifurcation (Figure $2 \mathrm{H}$ ) is rarely observed. In the other trifurcation subtypes, the MCA bifurcates and the dominant branch subsequently bifurcates again to give rise to a middle branch. In pseudotrifurcation (Figure 2l), the first and second bifurcation is less than $2 \mathrm{~mm}$ apart. With proximal trifurcation (Figure 2J), the most common subtype, the two bifurcations are more than $2 \mathrm{~mm}$ apart. In distal trifurcation (Figure $2 \mathrm{~K}$ ) the two bifurcations are more than $2 \mathrm{~mm}$ apart, and more than a quarter of the distance between the MCA origin and the first bifurcation (28).

Other branching types: Grellier et al. (19) described monofurcation as branching after the limen insulae, although monofurcation can also be termed when there is no division of the main trunk. Tetrafurcation (Figure 2B) is when the branching forms four trunks, and pseudotetrafurcation (Figure 2C) is when both the inferior and superior trunks bifurcate again near the initial bifurcation (25).

The prevalence of the branching types and subtypes is summarized in Table I. Monofurcation was observed in 3.8\% to $17.5 \%$ of cases, bifurcation was present in $64.3 \%$ to $92.7 \%$ of cases, and trifurcation was found in $7.0 \%$ to $61.0 \%$ in previous literature. Pseudotrifurcation was reported in $3.0 \%$ (three cases) (1), $15.0 \%$ (five cases) (28) and $20.0 \%$ (two cases) (59) in previous studies. Kahilogullari et al. (28) observed proximal trifurcation in 55.0\% (18 cases) and distal trifurcation in $30.0 \%$ (ten cases). Tetrafurcation was present in $0.7 \%$ to $10.0 \%(17,55,82-84)$ of cases, and pseudotetrafurcation was reported in one case (3.3\%) (25).

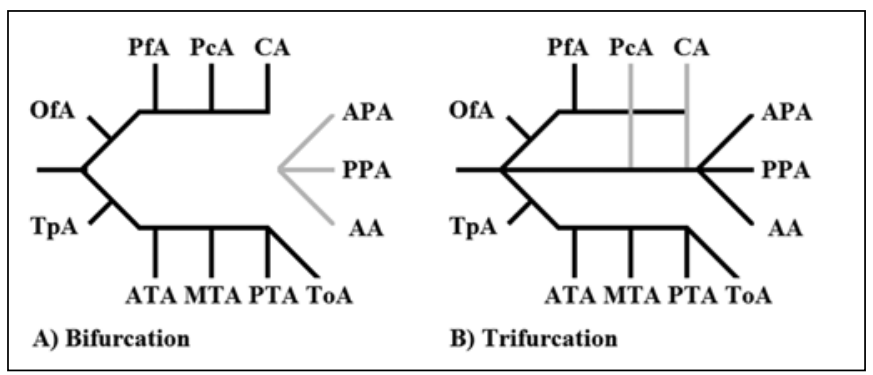

Figure 1: The most common origins of the cortical branches originating from the superior, inferior and middle trunk (grey illustrates more than one typical origin). (AA) Angular artery; (APA) Anterior parietal artery; (ATA) Anterior temporal artery; (CA) Central artery; (MTA) Middle temporal artery; (OfA) Orbitofrontal artery; (PcA) Precentral artery; (PfA) Prefrontal artery; (PPA) Posterior parietal artery; (PTA) Posterior temporal artery; (ToA) Temporooccipital artery; and (TpA) Temporopolar artery. 
Table I: The Prevalence of Monofurcation, Bifurcation, Trifurcation and Tetrafurcation

\begin{tabular}{|c|c|c|c|c|c|c|c|c|c|}
\hline \multirow[b]{2}{*}{ Authors } & \multirow[b]{2}{*}{ Total } & \multicolumn{2}{|c|}{ Monofurcation } & \multicolumn{2}{|c|}{ Bifurcation } & \multicolumn{2}{|c|}{ Trifurcation } & \multicolumn{2}{|c|}{ Tetrafurcation } \\
\hline & & Cases & $\%$ & Cases & $\%$ & Cases & $\%$ & Cases & $\%$ \\
\hline Jain (1964) (27) & 300 & - & - & 270 & $90.0 \%$ & 30 & $10.0 \%$ & - & - \\
\hline Grellier et al. (1978) (19) & 280 & 49 & $17.5 \%$ & 199 & $71.1 \%$ & 32 & $11.4 \%$ & - & - \\
\hline Gibo et al. (1981) (17) & 50 & - & - & 39 & $78.0 \%$ & 6 & $12.0 \%$ & 5 & $10.0 \%$ \\
\hline Umansky et al. (1984) (84) & 70 & 4 & $5.7 \%$ & 45 & $64.3 \%$ & 20 & $28.6 \%$ & 1 & $1.4 \%$ \\
\hline Antunes (1985) (2) & 37 & - & - & 33 & $89.2 \%$ & 4 & $10.8 \%$ & - & - \\
\hline Umansky et al. (1985) (83) & 34 & - & - & 24 & $70.6 \%$ & 7 & $20.6 \%$ & 3 & $8.8 \%$ \\
\hline Umansky et al. (1988) (82) & 104 & 4 & $3.8 \%$ & 69 & $66.3 \%$ & 27 & $26.0 \%$ & 4 & $3.8 \%$ \\
\hline Anderhuber et al. (1990) (1) & 100 & - & - & - & - & 7 & $7.0 \%$ & - & - \\
\hline Meneses et al. (1997) (47) & 14 & 1 & $7.1 \%$ & 12 & $85.7 \%$ & 1 & $7.1 \%$ & - & - \\
\hline Idowu et al. (2002) (23) & 100 & 6 & $6.0 \%$ & 81 & $81.0 \%$ & 13 & $13.0 \%$ & - & - \\
\hline Kulenović et al. (2003) (40) & - & - & - & - & $70.0 \%$ & - & $30.0 \%$ & - & - \\
\hline Tanriover et al. (2003) (71) & 50 & - & - & 44 & $88.0 \%$ & 6 & $12.0 \%$ & - & - \\
\hline Tanriover et al. (2004) (72) & 43 & - & - & 38 & $88.4 \%$ & 5 & $11.6 \%$ & - & - \\
\hline Pai et al. (2005) (59) & 10 & - & - & 8 & $80.0 \%$ & - & - & - & - \\
\hline Vuillier et al. (2008) (87) & 100 & 17 & $17.0 \%$ & 73 & $73.0 \%$ & 9 & $9.0 \%$ & - & - \\
\hline Nowinski et al. (2009) (53) & - & - & - & - & $78.0 \%$ & - & $12.0 \%$ & - & - \\
\hline Ogeng'o et al. (2011) (55) & 288 & 18 & $6.3 \%$ & 237 & $82.3 \%$ & 31 & $10.8 \%$ & 2 & $0.7 \%$ \\
\hline Sadatomo et al. (2013) (64) & 124 & - & - & 115 & $92.7 \%$ & 9 & $7.3 \%$ & - & - \\
\hline
\end{tabular}

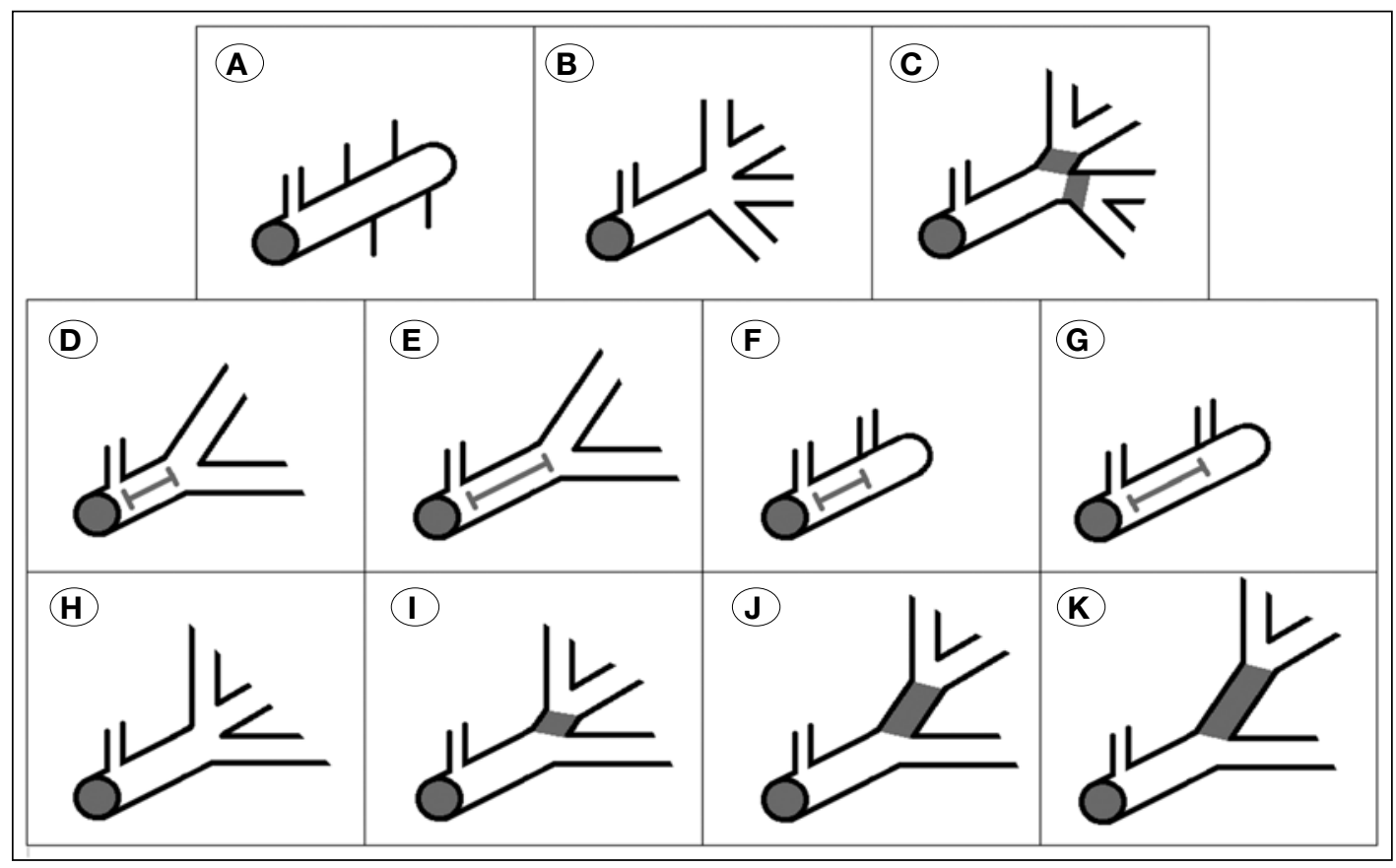

Figure 2: The 11 different branching patterns of the middle cerebral artery.

A) monofurcation;

B) tetrafurcation;

C) pseudotetrafurcation;

D) medial bifurcation;

E) lateral bifurcation;

F) medial

pseudobifurcation;

G) lateral

pseudobifurcation;

H) true trifurcation;

I) pseudotrifurcation; J) proximal trifurcation; and $\mathbf{K}$ ) distal trifurcation. 
Early branching: Excluding the bifurcation subtypes, the other branching types do not specify any criteria for how far from the MCA origin it can be observed. If branching occurs within $5 \mathrm{~mm}$ from the MCA origin, it is referred to as early branching $(31,55,73,77)$. Early branching has also been defined as branching within the proximal half of the M1 segment (90). Grellier et al. (19) stated that the main trunk could be either short (3-12 mm), medium (13-22 mm) or long (23-40 mm). The short length could refer to early branching; however, most authors $(31,55,73,77)$ agree that branching within $5 \mathrm{~mm}$ is referred to as early branching. Teal et al. (73) reported three cases, one branched at $3 \mathrm{~mm}$ and two branched at $4 \mathrm{~mm}$ from the MCA origin. Forty-three cases of early branching have been reported in previous literature, with a range of $2.7 \%$ to $11.3 \%(2,18,31,32,55,58)$. Early branching can be observed unilaterally or bilaterally (60).

\section{Anomalies}

True anomalies occur more frequently in other cerebral arteries compared to the MCA, although the three most common anomalies include fenestration, a duplicated MCA and an accessory MCA (Figure 3A-K) $(17,23,25,36,56,57,73,82)$. The duplicated and accessory MCAs are additional branches; the accessory MCA arises from the anterior cerebral artery, while a duplicated MCA originates from the internal carotid artery (ICA) $(5,17,37,39,73)$. The duplicated MCA usually supplies the temporal lobe and the accessory MCA typically supplies the frontal lobe $(25,30,57,60,77,80)$.

Duplicated middle cerebral artery: Two subtypes can be defined concerning origin and diameter (Figures 3F and 3G). Type A (most common) has a similar diameter compared to the main MCA trunk and arises from the top of the ICA (a more distal origin). Type $B$ has a smaller diameter compared to the main MCA trunk and arises between the top of the ICA and anterior choroidal artery (a more proximal origin) $(29,50)$. Type A can be regarded as an atypical early arising MCA trunk, and Type B as an atypical early arising MCA cortical branch (6).

The duplicated MCA was present in $0.3 \%$ to $7.1 \%$ (Table II) of cases in the literature. Kobari et al. (36) observed two additional branches (triplicated MCA), and all three branches originated from the ICA. Lame et al. (43) observed a "crossover" duplicated MCA that supplied the right hemisphere despite the branch originating from the left ICA.

Accessory middle cerebral artery: Compared to a duplicated MCA, the accessory MCA is typically smaller and consequently supplies a smaller area (37). The accessory MCA usually arises from the A1 segment close to the origin of

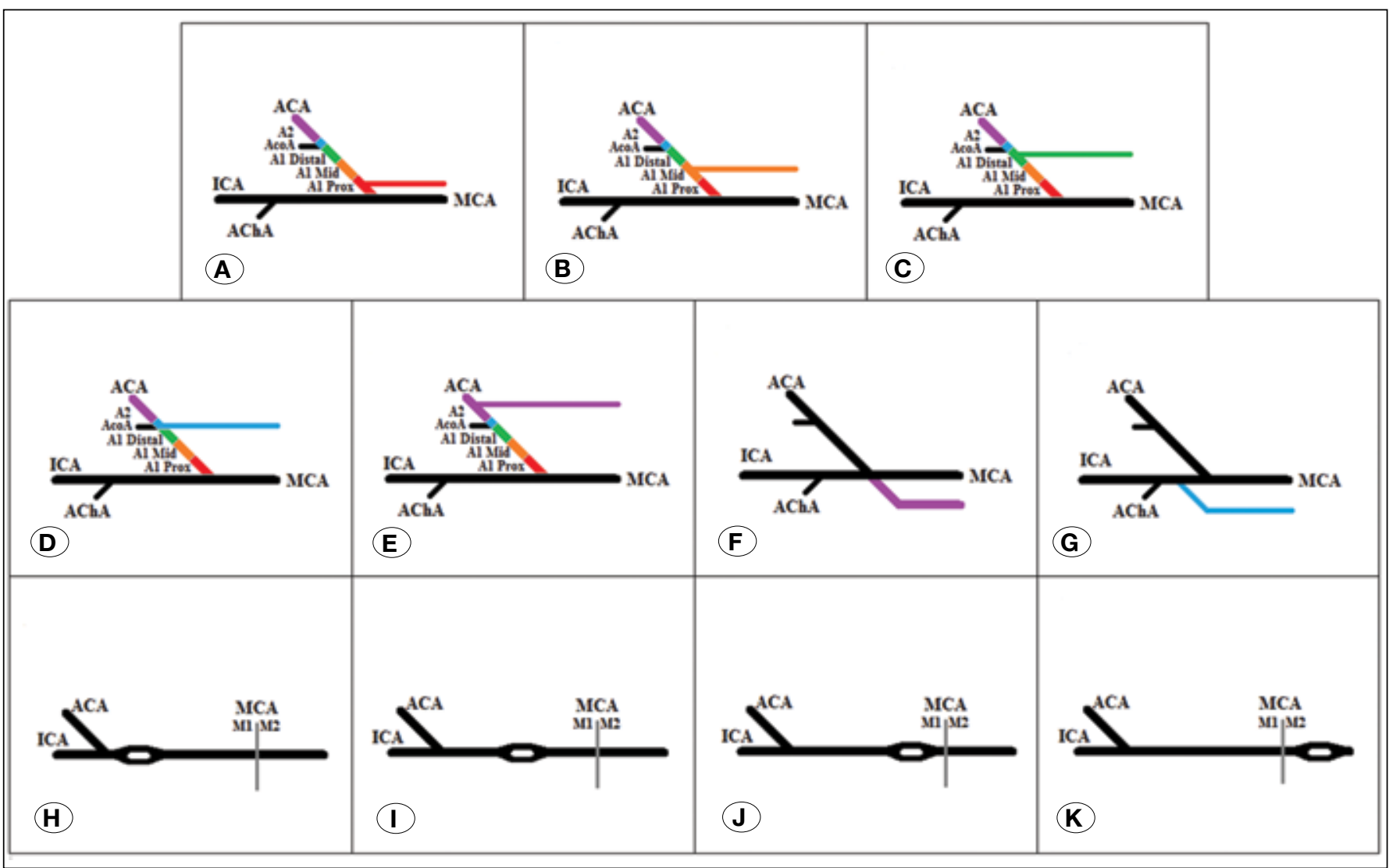

Figure 3: Anomalies of the middle cerebral artery. A) Accessory MCA from proximal A1 segment; B) accessory MCA from middle A1 segment; C) accessory MCA from distal A1 segment; D) accessory MCA from AcoA level; E) accessory MCA from A2 segment; F) duplicated MCA Type A; G) duplicated MCA Type B; H) proximal M1 fenestration; I) intermediate M1 fenestration; J) distal M1 fenestration; and K) M2 segment fenestration. 
Table II: The Prevalence of Duplicated and Accessory MCAs, and MCA Fenestration

\begin{tabular}{|c|c|c|c|c|c|c|c|}
\hline \multirow[b]{2}{*}{ Authors } & \multirow[t]{2}{*}{ Total } & \multicolumn{2}{|c|}{ Duplicated MCA } & \multicolumn{2}{|c|}{ Accessory MCA } & \multicolumn{2}{|c|}{ Fenestration } \\
\hline & & Cases & $\%$ & Cases & $\%$ & Cases & $\%$ \\
\hline Crompton (1962) (9) & 347 & 10 & $2.9 \%$ & 1 & $0.3 \%$ & 1 & $0.3 \%$ \\
\hline Jain (1964) (27) & 300 & 2 & $0.7 \%$ & 8 & $2.7 \%$ & - & - \\
\hline Wollschlaeger et al. (1967) (89) & 582 & - & - & - & - & 1 & $0.2 \%$ \\
\hline Ito et al. (1977) (26) & 1129 & - & - & - & - & 3 & $0.3 \%$ \\
\hline Grellier et al. (1978) (19) & 280 & 1 & $0.4 \%$ & 3 & $1.1 \%$ & - & - \\
\hline Milenković (1981) (48) & 60 & 1 & $1.7 \%$ & - & - & - & - \\
\hline Kayembe et al. (1984) (32) & 44 & - & - & 4 & $9.1 \%$ & - & - \\
\hline Kayembe et al. (1984) (32) & 146 & - & - & 10 & $6.8 \%$ & - & - \\
\hline Umansky et al. (1984) (84) & 70 & - & - & 2 & $2.9 \%$ & - & - \\
\hline Antunes (1985) (2) & 37 & - & - & - & - & 1 & $2.7 \%$ \\
\hline Kitami et al. (1985) (35) & 704 & 6 & $0.9 \%$ & 4 & $0.6 \%$ & 4 & $0.6 \%$ \\
\hline Tran-Dinh (1986) (74) & 150 & - & - & 3 & $2.0 \%$ & - & - \\
\hline Umansky et al. (1988) (82) & 104 & 1 & $1.0 \%$ & 2 & $1.9 \%$ & 1 & $1.0 \%$ \\
\hline Yamamoto et al. (1992) (90) & 455 & 7 & $1.5 \%$ & 14 & $3.1 \%$ & - & - \\
\hline Sanders et al. (1993) (65) & 5190 & - & - & - & - & 9 & $0.2 \%$ \\
\hline Meneses et al. (1997) (47) & 14 & 1 & $7.1 \%$ & 1 & $7.1 \%$ & - & - \\
\hline Ozaki et al. (1997) (58) & 153 & 2 & $1.6 \%$ & 9 & $5.9 \%$ & - & - \\
\hline Uchino et al. (2000) (76) & 425 & 9 & $2.1 \%$ & 5 & $1.2 \%$ & 2 & $0.5 \%$ \\
\hline Gailloud et al. (2002) (15) & 1170 & - & - & - & - & 5 & $0.4 \%$ \\
\hline Idowu et al. (2002) (23) & 100 & - & - & 1 & $1.0 \%$ & - & - \\
\hline Tanriover et al. (2003) (71) & 50 & 1 & $2.0 \%$ & 2 & $4.0 \%$ & - & - \\
\hline Uchino et al. (2003) (78) & 900 & 14 & $1.6 \%$ & - & - & - & - \\
\hline Karazincir et al. (2004) (31) & 176 & 1 & $0.6 \%$ & - & - & - & - \\
\hline Tanriover et al. (2004) (72) & 43 & - & - & 2 & $4.7 \%$ & - & - \\
\hline Kim et al. (2005) (33) & 448 & 2 & $0.4 \%$ & 2 & $0.4 \%$ & 2 & $0.4 \%$ \\
\hline Kim et al. (2005) (33) & 743 & 6 & $0.8 \%$ & 1 & $0.1 \%$ & 1 & $0.1 \%$ \\
\hline D’Ávila \& Schneider (2006) (10) & 50 & - & - & 1 & $2.0 \%$ & - & - \\
\hline Bharatha et al. (2008) (4) & 504 & - & - & - & - & 2 & $0.4 \%$ \\
\hline Vuillier et al. (2008) (87) & 100 & - & - & - & - & 3 & $3.0 \%$ \\
\hline Gielecki et al. (2009) (18) & 304 & 2 & $0.7 \%$ & - & - & - & - \\
\hline Kim \& Lee (2009) (34) & 1250 & - & - & 16 & $1.3 \%$ & - & - \\
\hline van Rooij et al. (2009) (85) & 208 & - & - & - & - & 12 & $5.8 \%$ \\
\hline Bayrak et al. (2011) (3) & 395 & - & - & - & - & 4 & $1.0 \%$ \\
\hline Chang \& Kim (2011) (6) & 1250 & 9 & $0.7 \%$ & - & - & - & - \\
\hline Chang \& Kim (2011) (6) & 1452 & 9 & $0.6 \%$ & - & - & - & - \\
\hline
\end{tabular}


Table II: Cont.

\begin{tabular}{|c|c|c|c|c|c|c|c|}
\hline Authors & Total & \multicolumn{2}{|c|}{ Duplicated MCA } & \multicolumn{2}{|c|}{ Accessory MCA } & \multicolumn{2}{|c|}{ Fenestration } \\
\hline Chang \& Kim (2011) (6) & 2527 & 7 & $0.3 \%$ & - & - & - & - \\
\hline Ogeng'o et al. (2011) (55) & 288 & 5 & $1.7 \%$ & - & - & - & - \\
\hline Sun et al. (2012) (68) & 4652 & - & - & - & - & 3 & $0.06 \%$ \\
\hline Hamidi et al. (2013) (21) & 500 & 7 & $1.4 \%$ & 1 & $0.2 \%$ & 10 & $2.0 \%$ \\
\hline Cooke et al. (2014) (8) & 10927 & - & - & - & - & 10 & $0.09 \%$ \\
\hline Kovač et al. (2014) (38) & 455 & - & - & - & - & 1 & $0.2 \%$ \\
\hline van Rooij et al. (2015) (86) & 140 & - & - & - & - & 4 & $2.9 \%$ \\
\hline
\end{tabular}

the anterior communicating artery $(A c o A)(9,17,63,71,84,91)$, although, the accessory MCA can be classified into five different subtypes with regards to the region of the anterior cerebral artery it arises from (Figures 3A-E). This branch can originate from the $A 1$ segment (proximal $(33,76)$, middle (34) or distal part $(33,76)$, at the AcoA level, or from the A2 segment (34).

The accessory MCA was observed in $0.1 \%$ to $9.1 \%$ (Table II) by previous authors. Two accessory MCAs can be present in the same hemisphere (88) and Kim and Lee (34) reported a case of bilateral accessory MCAs. Gibo et al. (17) and Kitami et al. (35) described a hemisphere with an accessory and a duplicated MCA.

Fenestration: Fenestration is when a vessel has a common origin, splits into two channels and then rejoins $(4,15,60)$. These fenestrations can be either small slit-like or large convex-like $(8,79)$ and small slit-like fenestrations are the most common (18). Fenestrations of the MCA are typically observed in the M1 segments, although it can also be present in the M2 segment (Figure 3K). Three subtypes of M1 segment fenestrations can be defined; the proximal, intermediate and distal type (Figures $3 \mathrm{H}, \mathrm{I}, \mathrm{J}$ ). Fenestration of the proximal M1 segment is the most common $(11,25,26,33,52,66,76,79))$. Middle cerebral artery fenestrations were present in $0.1 \%$ to $5.8 \%$ (Table II) of cases in the literature. Several previous studies noted that the temporopolar artery frequently arises as an early temporal branch in association with fenestrations $(15,25,26,33,60,77,79)$.

Selected authors noted an association between duplicated MCAs and aneurysms $(50,61,62)$, although very few studies have reported aneurysms at the origin or near the anomalous branch $(12,24,29,42,49,57,70)$. Several authors observed an association between accessory MCAs and aneurysms $(30,80,91)$. Few studies have, however, reported aneurysms at the origin or near the anomalous branch $(14,16,22,41,45,46,51,67,88)$. Fenestration might predispose patients to aneurysm formation (62) and selected authors have observed an association between fenestration and aneurysms (proximal or distal to the fenestration) $(13,44,52,54,62,65,81)$.
Limited studies have, however, reported aneurysms at the site of the MCA fenestration $(11,26,66,69)$. Furthermore, van Rooij et al. (85) noted that fenestrations with and without aneurysms were not statistically significantly different.

In summary, information on the origin of the cortical branches is available; however, cortical branches arising from or in conjunction with another cortical branch have not been described. Additionally, few reports have been given on the diameter, length, absence and duplication of MCA cortical branches. Eleven different branching types can be distinguished from the literature; however, some criteria are still lacking. The prevalence of the MCA anomalies has been adequately reported in the literature; however, few studies mention the different subtypes. Therefore, a pilot study was done to fill these gaps.

\section{PILOT STUDY}

For the pilot study, 20 hemispheres were perfused with colored silicone and the MCA was dissected (Figure 4). The diameter and length of the cortical branches were measured, any absent or duplicated arteries were reported, and the origins were noted. The diameter was measured using a digital micrometer and the length was measured using string and a ruler. The branching pattern was identified and any anomalies were noted.

\section{RESULTS}

\section{Cortical Branches}

There is substantial deviation in the size, number and origin of the MCA cortical branches (17). Table III gives the frequency that each cortical branch was observed and duplicated. The average diameter and length of each cortical branch is noted, as well as the origins.

The temporopolar artery was the smallest and shortest artery and the posterior parietal artery was the largest and longest cortical branch. Most commonly absent was the common temporal artery in $65.0 \%$ and most commonly duplicated was 
the anterior parietal artery in $30.0 \%$. There were no triplicated cortical branches.

The inferior trunk usually gave rise to the temporal arteries and the superior trunk typically gave rise to the OfA, PfA, precentral and central arteries. The angular artery and parietal arteries originated from either the superior or the inferior trunk. The temporopolar artery (54.5\%) and the prefrontal artery (27.8\%) typically originated as early branches. Common

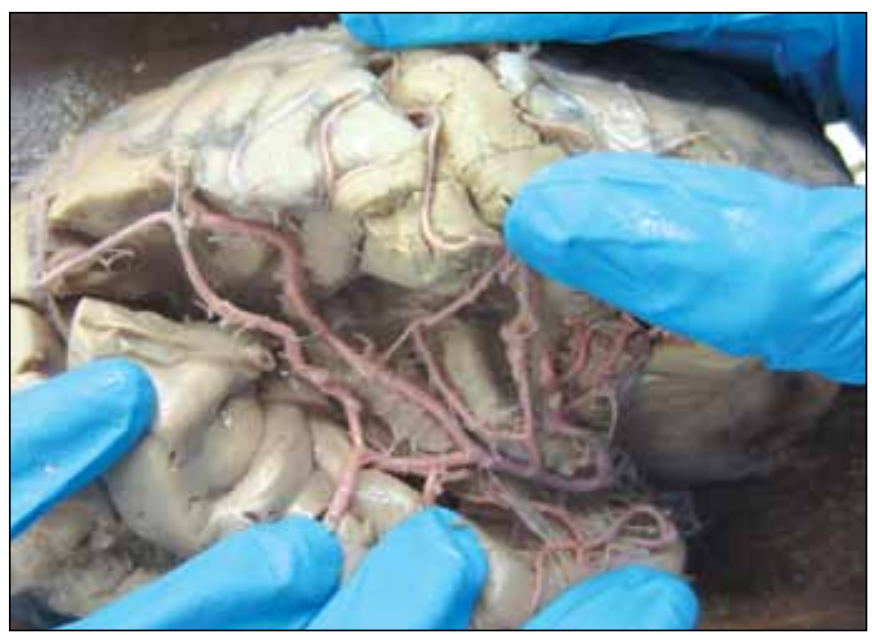

Figure 4: Illustration of the middle cerebral artery perfused with a colored silicone. trunks included the PfA and precentral artery in $42.1 \%$, the temporopolar artery and ATA in $31.6 \%$, and the PcA and central artery in $31.6 \%$ of cases.

\section{Branching Pattern}

Eleven different branching types can be distinguished from the literature (Figure 2A-K). However, the precise distances used to classify the different branching subtypes are not reported in previous studies. Since most authors define early branching as branching before $5 \mathrm{~mm}(40,71)$, medial and lateral branching were defined as branching between $5 \mathrm{~mm}$ and $20 \mathrm{~mm}$, and branching after $20 \mathrm{~mm}$, respectively.

The bifurcation subtypes that were observed included medial bifurcation (50.0\%), lateral bifurcation $(25.0 \%)$, and lateral pseudobifurcation (5.0\%). Medial pseudobifurcation was not observed. Trifurcation subtypes that were observed included proximal trifurcation $(10.0 \%)$ and distal trifurcation $(5.0 \%)$. True trifurcation and pseudotrifurcation were not observed. Not all studies differentiate between true trifurcation and pseudotrifurcation since these branching types are very similar. Nevertheless, this distinction is important to determine the correct prevalence of these branching types. Tetrafurcation and pseudotetrafurcation were not observed, however, one case of monofurcation was present. The prevalence of these branching subtypes has a large range, and this may indicate that authors do not always use the same criteria for the same branching types.

Table III: The Average Diameter ( $\mathrm{mm})$, Average Length $(\mathrm{mm})$, Presence, Duplication and Origins of the Middle Cerebral Cortical Branches Observed in the Pilot Study

\begin{tabular}{|c|c|c|c|c|c|c|c|c|c|c|c|c|c|}
\hline & OfA & PfA & PcA & CA & APA & PPA & AA & ToA & CTA & TpA & ATA & MTA & PTA \\
\hline Presence & 95.0 & 90.0 & 95.0 & 100 & 90.0 & 100 & 95.0 & 65.0 & 35.0 & 60.0 & 95.0 & 90.0 & 90.0 \\
\hline Duplication & 15.0 & 5.0 & 25.0 & 25.0 & 30.0 & 15.0 & 5.0 & - & - & - & - & - & 5.0 \\
\hline Diameter & 1.4 & 1.5 & 1.3 & 1.4 & 1.4 & 1.5 & 1.5 & 1.5 & 1.5 & 1.1 & 1.2 & 1.1 & 1.4 \\
\hline Length & 33.1 & 43.3 & 63.5 & 65.0 & 74.6 & 90.9 & 90.0 & 81.6 & 33.7 & 33.0 & 38.7 & 61.9 & 66.0 \\
\hline EB & $23.8 \%$ & $22.2 \%$ & - & - & - & - & - & - & $16.7 \%$ & $54.5 \%$ & $27.8 \%$ & - & $16.7 \%$ \\
\hline INF & - & - & - & $4.3 \%$ & $17.4 \%$ & $40.9 \%$ & $78.9 \%$ & $91.7 \%$ & $66.7 \%$ & $27.3 \%$ & $50.0 \%$ & $47.1 \%$ & $61.1 \%$ \\
\hline SUP & $47.6 \%$ & $77.8 \%$ & $95.7 \%$ & $91.3 \%$ & $78.3 \%$ & $50.0 \%$ & $21.1 \%$ & $8.3 \%$ & - & - & - & - & - \\
\hline CTA & - & - & - & - & - & - & - & - & - & $18.2 \%$ & $22.2 \%$ & $29.4 \%$ & $11.1 \%$ \\
\hline PfA & $28.6 \%$ & - & - & - & - & - & - & - & - & - & - & - & - \\
\hline PcA & - & - & - & $4.3 \%$ & - & - & - & - & - & - & - & - & - \\
\hline CA & - & - & $4.3 \%$ & - & $4.3 \%$ & - & - & - & - & - & - & - & - \\
\hline AA & - & - & - & - & - & $9.1 \%$ & - & - & - & - & - & - & - \\
\hline ToA & - & - & - & - & - & - & - & - & - & - & - & $5.9 \%$ & $11.1 \%$ \\
\hline PTA & - & - & - & - & - & - & - & - & $16.7 \%$ & - & - & $17.6 \%$ & - \\
\hline
\end{tabular}

Monofurcation was excluded for origins. AA: Angular artery, APA: Anterior parietal artery, ATA: Anterior temporal artery, CA: Central artery, EB: Early branches, INF: Inferior trunk, MTA: Middle temporal artery, OfA: Orbitofrontal artery, PcA: Precentral artery, PfA: Prefrontal artery, PPA: Posterior parietal artery, PTA: Posterior temporal artery, ToA: Temporo-occipital artery, TpA: Temporopolar artery, and SUP: Superior trunk. 


\section{Anomalies}

Unfortunately, there were no MCA anomalies observed in the 20 hemispheres. The average prevalence of the MCA anomalies calculated from Table II are very low [accessory MCA (1.4\%), duplicated MCA (0.9\%) and MCA fenestration $(0.3 \%)]$. This low prevalence indicates that a larger sample size is needed.

\section{DISCUSSION}

This study reviewed the available literature on the cortical branches, branching pattern and anomalies of the MCA. A pilot study was done to fill the gaps that were identified. Limited research with regard to the diameters, length, presence and duplication of the MCA cortical branches have been done, therefore these aspects were reported in the pilot study. The origins and possible common trunks are also not thoroughly discussed in the literature and were thus noted in the pilot study. The MCA branching types have been discussed in previous studies, although the subtypes are normally neglected. The criteria for each branching subtype has not been previously described, therefore this was described in the pilot study. The branching types were identified in the 20 hemispheres and an illustration of the different subtypes is given to ensure there is no confusion on these subtypes in future studies. Although there were no MCA anomalies observed in the pilot study, the review summarized the prevalence and described the different subtypes. An illustration of these anomalies is given to ensure future studies can correctly classify the anomalies, and consequently be able to mention the specific subtypes.

A shorter length may play a role in aneurysms formation and changes in diameter can indicate certain diseases (92). Knowing the range of these aspects is therefore important. Aneurysms are frequently observed at areas where branching occurs; therefore, knowledge on the different patterns is crucial for aneurysm related surgeries $(17,28,55)$. The accessory or duplicated MCA can offer potential collateral supply in the event of a stroke; therefore, the clinical signs of a stroke can be confusing if the anatomy of the MCA is not known $(27,55,73,84)$. Furthermore, these anomalies may be associated with aneurysms.

\section{CONCLUSION}

Certain aspects of the MCA anatomy have been neglected. Future studies should give adequate descriptions of the MCA cortical branches, MCA branching pattern, and any anomalies observed.

\section{- ACKNOWLEDGEMENTS}

The author's would like to thank the Harry Crossley Foundation, Mr. R.P. Williams and the relevant individuals concerning cadaver donation.

\section{REFERENCES}

1. Anderhuber F, Weiglein A, Pucher RK: Trifurcations of the middle cerebral arteries. Acta Anat 137(4):342-349, 1990

2. Antunes ACM: The microsurgical anatomy of the human middle cerebral artery. Arq Bras Neurochir 4:195-208, 1985

3. Bayrak AH, Senturk S, Akay HO, Ozmen CA, Bukte Y, Nazaroglu $\mathrm{H}$ : The frequency of intracranial arterial fenestrations: A study with 64-detector CT-angiography. Eur J Radiol 77(3):392-396, 2011

4. Bharatha A, Aviv RI, White J, Fox AJ, Symons SP: Intracranial arterial fenestrations: Frequency on CT angiography and association with other vascular lesions. Surg Radiol Anat 30(5):397-401, 2008

5. Bradac GB: Cerebral Angiography- Normal Anatomy and Vascular Pathology. London: Springer, 2011

6. Chang HY, Kim MS: Middle cerebral artery duplication: Classification and clinical implications. J Korean Neurosurg Soc 49(2):102-106, 2011

7. Ciszek B, Aleksandrowicz R, Zabek M, Mazurowski W: Classification, topography and morphometry of the early branches of the middle cerebral artery. Folia Morphol (Warsz) 55(4):229-230, 1996

8. Cooke DL, Stout CE, Kim WT, Kansagra AP, Yu JP, Gu A, Halbach VV: Cerebral arterial fenestrations. Interv Neuroradiol 20(3):261-274, 2014

9. Crompton MR: The pathology of ruptured middle-cerebral aneurysms with special references to the differences between the sexes. Lancet 2(7253):421-425, 1962

10. D'Ávila AA, Schneider FL: Microsurgical anatomy of the human basal anterior perforated substance. Arq Neuropsiquiatr 64(2):249-258, 2006

11. Deruty R, Pelissou-Guyotat I, Mottolese C, Bognar L, Laharotte JC, Turjman F: Fenestration of the middle cerebral artery and aneurysm at the site of the fenestration. J Neurosci Res 14(5):421-424, 1992 (Abstract)

12. Elsharkawy A, Ishii $K$, Niemelä $M$, Kivisaari $R$, Lehto $H$, Hernesniemi J: Management of aneurysms at the origin of duplicated middle cerebral artery: Series of four patients with review of the literature. World Neurosurg 80(6):313-318, 2013

13. Fujimura M, Seki $H$, Sugawara T, Tomichi N, Oku T, Higuchi $\mathrm{H}$ : Anomalous internal carotid artery-anterior cerebral artery anastomosis associated with fenestration and cerebral aneurysm. Neurol Med Chir (Tokyo) 36(4):229-233, 1996

14. Fujiwara K, Saito K, Ebina T: Saccular aneurysm of the accessory middle cerebral artery-case report. Neurol Med Chir (Tokyo) 43(1):31-24, 2003

15. Gailloud P, Albayram S, Fasel JH, Beauchamp NJ, Murphy KJ: Angiographic and embryologic considerations in five cases of middle cerebral artery fenestration. AJNR Am J Neuroradiol 23(4):585-587, 2002

16. Georgopoulos CE, Papanikolaou PG, Vlachos KI, AtzemiMoldow N, Hatzidakis Gl: Ruptured aneurysm at the trunk of the accessory middle cerebral artery. Acta Neurochir (Wien) 141(11):1233-1235, 1999

17. Gibo H, Carver CC, Rhoton AL, Lenkey C, Mitchell RJ: Microsurgical anatomy of the middle cerebral artery. J Neurosurg 54:151-169, 1981 
18. Gielecki J, Zurada A, Kozłowska H, Nowak D, Loukas M: Morphometric and volumetric analysis of the middle cerebral artery in human fetuses. Acta Neurobiol Exp (Wars) 69(1):129137, 2009

19. Grellier P, Roche JL, Duplay J: Radio-anatomical study of the main trunk of the middle cerebral artery. Neurochirurgie 24(4):227-233, 1978

20. Gunnal SA, Wabale RN, Farooqui MS: Variations of anterior cerebral artery in human cadavers. Neurol Asia 18(3):249-259, 2013

21. Hamidi C, Bukte Y, Hattapoglu S, Ekici F, Tekbas G, Onder $H$, Gumus H, Bilici A: Display with 64-detector MDCT angiography of cerebral vascular variations. Surg Radiol Anat 35(8):729-736, 2013

22. Han DH, Gwak HS, Chung CK: Aneurysm at the origin of accessory middle cerebral artery associated with middle cerebral artery aplasia: Case report. Surg Neurol 42(5):388391, 1994

23. Idowu OE, Shokunbi MT, Malomo AO, Ogunbiyi JO: Size, course, distribution and anomalies of the middle cerebral artery in adult Nigerians. East Afr Med J 79(4):217-220, 2002

24. Imaizumi S, Onuma T, Motohashi $O$, Kameyama $M$, Ishii $\mathrm{K}$ : Unruptured carotid-duplicated middle cerebral artery aneurysm: Case report. Surg Neurol 58(5):322-324, 2002

25. Isolan GR, de Aguiar PHP, Aires R, Meister CS, Stefani MA: Middle cerebral artery "Pseudotetrafurcation": Anatomic report and review of middle cerebral artery variations. Neurosurgery 20(4):284-287, 2010

26. Ito J, Maeda H, Inoue K, Onishi Y: Fenestration of the middle cerebral artery. Neuroradiology 13(1):37-39, 1977

27. Jain KK: Some observations on the anatomy of the middle cerebral artery. Can J Surg 7:134-139, 1964

28. Kahilogullari G, Ugur HC, Comert A, Tekdemir I, Kanpolat $Y$ : The branching pattern of the middle cerebral artery: Is the intermediate trunk real or not? An anatomical study correlating with simple angiography Laboratory investigation. J Neurosurg 116(5):1024-1034, 2012

29. Kai Y, Hamada J, Morioka M, Yano S, Kudo M, Kuratsu J: Treatment of unruptured duplicated middle cerebral artery aneurysm: Case report. Surg Neurol 65(2):190-193, 2006

30. Kang DH, Park J, Park SH, Hamm IS: Saccular aneurysm at the anterior communicating artery complex associated with an accessory middle cerebral artery: Report of two cases and review of the literature. J Korean Neurosurg Soc 46(6):568571,2009

31. Karazincir S, Ada E, Sarsilmaz A, Yalçin O, Vidinli B, Sahin E: Frequency of vascular variations and anomalies accompanying intracranial aneurysms. Diagn Interv Radiol 10(2):103-109, 2004

32. Kayembe KN, Sasahara M, Hazama F: Cerebral aneurysms and variations in the circle of Willis. Stroke 15(5):846-850, 1984

33. Kim MS, Hur JW, Lee JW, Lee HK: Middle cerebral artery anomalies detected by conventional angiography and magnetic resonance angiography. J Korean Neurosurg Soc 37:263-267, 2005
34. Kim MS, Lee HK: The angiographic feature and clinical implication of accessory middle cerebral artery. J Korean Neurosurg Soc 45(5):289-292, 2009

35. Kitami K, Kamiyama H, Yasui N: Angiographic analysis of the middle cerebral artery in cerebral aneurysms-its branching pattern and so-called vascular anomalies. No Shinkei Geka 13(3):283-290, 1985 (Abstract)

36. Kobari M, Ishihara N, Yunoki K, Togashi O, Sato S: Triplication of the middle cerebral artery associated with fenestration of the anterior cerebral artery. Keio J Med 37(4):429-433, 1988

37. Komiyama $M$, Nishikawa $M$, Yasui $T$ : The accessory middle cerebral artery as a collateral blood supply. AJNR Am J Neuroradiol 18:587-590, 1997

38. Kovač JD, Stanković A, Stanković D, Kovač B, Šaranović D: Intracranial arterial variations: A comprehensive evaluation using CT angiography. Med Sci Monit 20:420, 2014

39. Krayenbuhl H, Yasargil MG, Huber P: Cerebral Angiography. Thieme Medical Publishers, 1982

40. Kulenović A, Dilberović F, Ovcina F: Variation in the flow and branching of the anterior and middle cerebral arteries. Med Arch 57(1):3-5, 2003 (Abstract)

41. Kuwabara S, Naitoh $\mathrm{H}$ : Ruptured aneurysm at the origin of the accessory middle cerebral artery: Case report. Neurosurgery 26(2):320-322, 1990 (Abstract)

42. LaBorde DV, Mason AM, Riley J, Dion JE, Barrow DL: Aneurysm of a duplicate middle cerebral artery. World Neurosurg 77(1):201-204, 2012

43. Lame A, Kaloshi G, Petrela M: Anatomic variants of accessory medial cerebral artery. Neurosurgery 66(6):1217, 2010

44. Lazar ML, Bland JE, North RR, Bringewald PR: Middle cerebral artery fenestration. Neurosurgery 6(3):297-300, 1980 (Abstract)

45. Lee CC, Liu ZH, Jung SM, Yang TC: Ruptured aneurysm of the accessory middle cerebral artery associated with moyamoya disease: A case report. Chang Gung Med J 34(5):541-547, 2011

46. Lee IH, Jeon P, Kim KH, Byun HS, Kim HJ, Kim ST, Kim JS: Endovascular treatment of a ruptured accessory middle cerebral artery aneurysm. J Clin Neurosci 17(3):383-384, 2010

47. Meneses MS, Ramina R, Jackowski AP, Pedrozo AA, Pacheco $\mathrm{RB}$, Tsubouchi $\mathrm{MH}$ : Middle cerebral artery revascularization. Anatomical studies and considerations on the anastomosis site. Arq Neuropsiquiatr 55(1):16-23, 1997

48. Milenković Z: Anastomosis between internal carotid artery and anterior cerebral artery with other anomalies of the circle of Willis in a fetal brain. J Neurosurg 55(5):701-703, 1981

49. Miyahara K, Fujitsu K, Ichikawa T, Mukaihara S, Okada T, Kaku S: Unruptured saccular aneurysm at the origin of the duplicated middle cerebral artery: Reports of two cases and review of the literature. No Shinkei Geka 37(12):1241-1245, 2009 (Abstract)

50. Miyamoto J, Mineura K: Unruptured middle cerebral artery aneurysm associated with a duplicated middle cerebral artery and a dolichoectasic anterior cerebral artery. J Stroke Cerebrovasc Dis 19(6):503-506, 2010 
51. Miyazaki S, Ito $\mathrm{K}$, Ishii S: Aneurysm at the origin of the accessory middle cerebral artery. Surg Neurol 22(3):292-294, 1984

52. Nakamura H, Takada A, Hide T, Ushio Y: Fenestration of the middle cerebral artery associated with an aneurysm: Case report. Neurol Med Chir (Tokyo) 34:555-557, 1994

53. Nowinski WL, Thirunavuukarasuu A, Volkau I, Marchenko Y, Aminah B, Puspitasari F, Runge VM: A three-dimensional interactive atlas of cerebral arterial variants. Neuroinformatics 7(4):255-264, 2009

54. Nussbaum ES, Defillo A, Janjua TM, Nussbaum LA: Fenestration of the middle cerebral artery with an associated ruptured aneurysm. J Clin Neurosci 16(6):845-847, 2009

55. Ogeng'o JA, Njongo W, Hemed E, Obimbo MM, Gimongo $\mathrm{J}$ : Branching pattern of middle cerebral artery in an African population. Clin Anat 24(6):692-698, 2011

56. Osborn AG, Jacobs JM: Diagnostic Cerebral Angiography. $2^{\text {nd }}$ ed. Lippincott Williams \& Wilkins, 1999

57. Otani N, Nawashiro H, Tsuzuki N, Osada H, Suzuki T, Shima K, Nakai K: A ruptured internal carotid artery aneurysm located at the origin of the duplicated middle cerebral artery associated with accessory middle cerebral artery and middle cerebral artery aplasia. Surg Neurol Int (1): 51, 2010

58. Ozaki T, Handa H, Tomimoto K, Hazama F: Anatomical variations of the arterial system of the base of the brain. Arch Japan Chir 46:3-17, 1977

59. Pai SB, Varma RG, Kulkarni RN: Microsurgical anatomy of the middle cerebral artery. Neurol India 53(2): 186-190, 2005

60. Parmar H, Sitoh YY, Hui F: Normal variants of the intracranial circulation demonstrated by MR angiography at $3 T$. Eur J Radiol 56(2):220-228, 2005

61. Perez J, Machado C, Scherle C, Hierro D: Duplicated middle cerebral artery. BMJ Case Reports 6:2009-2035, 2009

62. Rennert J, Ullrich WO, Schuierer G: A rare case of supraclinoid internal carotid artery (ICA) fenestration in combination with duplication of the middle cerebral artery (MCA) originating from the ICA fenestration and an associated aneurysm. Clin Neuroradiol 23(2):133-136, 2013

63. Rhoton AL: The supratentorial arteries. Neurosurgery 51(4):53120, 2002

64. Sadatomo T, Yuki K, Migita K, Imada Y, Kuwabara M, Kurisu K: Differences between middle cerebral artery bifurcations with normal anatomy and those with aneurysms. Neurosurg Rev 36(3):437-445, 2013

65. Sanders WP, Sorek PA, Mehta BA: Fenestration of intracranial arteries with special attention to associated aneurysms and other anomalies. AJNR Am J Neuroradiol 14(3):675-680, 1993

66. Sim KB, Lee CS, Park JC, Huh JS: Cerebral aneurysm in the long fenestration at the middle portion of M1 segment. J Korean Neurosurg Soc 48(5):434-437, 2010

67. Sugita S, Yuge T, Miyagi J, Fujimura N, Shigemori M: Giant aneurysm at the origin of the accessory middle cerebral artery. Surg Neurol 44(2):128-130, 1995

68. Sun ZK, Li M, Li MH, Li YD, Sun WP, Zhu YQ: Fenestrations accompanied by intracranial aneurysms assessed with magnetic resonance angiography. Neurol India 60(1):45, 2012
69. Tabuchi S, Yoshioka H: Ruptured aneurysm at the fenestration of the middle cerebral artery detected by magnetic resonance angiography in a patient with systemic lupus erythematosus and renal failure: A case report. J Med Case Rep 8:30, 2014

70. Tabuse $M$, Wakamoto $H$, Miyazaki $H$, Ishiyama $N$ : The usefulness of 3D-CTA for the diagnosis of a ruptured aneurysm at the origin of the duplicated middle cerebral artery: Case report. No Shinkei Geka 30(3):327-331, 2002 (Abstract)

71. Tanriover N, Kawashima M, Rhoton AL, Ulm AJ, Mericle RA: Microsurgical anatomy of the early branches of the middle cerebral artery: Morphometric analysis and classification with angiographic correlation. J Neurosurg 98:1277-1290, 2003

72. Tanriover N, Rhoton AL, Kawashima M, Ulm AJ, Yasuda A: Microsurgical anatomy of the insula and the sylvian fissure. $J$ Neurosurg 100(5):891-922, 2004

73. Teal JS, Rumbaugh CL, Bergeron RT, Segall HD: Anomalies of the middle cerebral artery: Accessory artery, duplication, and early bifurcation. AJR Am J Roentgenol 118(3):567-575, $1973 b$

74. Tran-Dinh $\mathrm{H}$ : The accessory middle cerebral artery-a variant of the recurrent artery of Heubner (A. centralis longa)? Acta Anat 126(3):167-171, 1986

75. Ture U, Yasargil MG, Al-Mefty O, Yasargil DC: Arteries of the insula. J Neurosurg 92(4):676-687, 2000

76. Uchino A, Kato A, Takase Y, Kudo S: Middle cerebral artery variations detected by magnetic resonance angiography. Eur J Radiol 10(4):560-563, 2000

77. Uchino A, Saito N, Okada Y, Nakajima R: Duplicate origin and fenestration of the middle cerebral artery on MR angiography. Surg Radiol Anat 34(5):401-404, 2012

78. Uchino A, Sawada A, Takase Y, Kudo S: MR angiography of anomalous branches of the internal carotid artery. AJR Am J Roentgenol 181(5):1409-1414, 2003

79. Uchino A, Takase Y, Nomiyama K, Egashira R, Kudo S: Fenestration of the middle cerebral artery detected by MR angiography. Magn Reson Med Sci 5(1):51-55, 2006

80. Uchino M, Kitajima S, Sakata Y, Honda M, Shibata I: Ruptured aneurysm at a duplicated middle cerebral artery with accessory middle cerebral artery. Acta Neurochir (Wien) 146(12):1373-1374, 2004

81. Ueda T, Goya T, Wakisaka S, Kinoshita K: Fenestrations of the middle cerebral artery associated with aneurysms. AJNR Am J Neuroradiol 5(5):639-640, 1984

82. Umansky F, Dujovny M, Ausman JI, Diaz FG, Mirchandani HG: Anomalies and variations of the middle cerebral artery: A microanatomical study. Neurosurgery 22(6 Pt 1):1023-1027, 1988

83. Umansky F, Gomes FB, Dujovny M, Diaz FG, Ausman JI, Haresh G, Mirchandani HG, Berman SK: The perforating branches of the middle cerebral artery: A microanatomical study. J Neurosurg 62:261-268, 1985

84. Umansky F, Juarez SM, Dujovny M, Ausman JI, Diaz FG, Gomes F, Mirchandani HG, Ray WJ: Microsurgical anatomy of the proximal segments of the middle cerebral artery. $J$ Neurosurg 61:458-467, 1984 
85. van Rooij S, van Rooij WJ, Sluzewski M, Sprengers ME: Fenestrations of intracranial arteries detected with 3D rotational angiography. AJNR Am J Neuroradiol 30(7):13471350, 2009

86. van Rooij SB, Bechan RS, Peluso JP, Sluzewski M, van Rooij WJ: Fenestrations of intracranial arteries. AJNR Am J Neuroradiol 36(6):1167-1170, 2015

87. Vuillier F, Medeiros E, Moulin T, Cattin F, Bonneville JF, Tatu $L$ : Main anatomical features of the M1 segment of the middle cerebral artery: A 3D time-of-flight magnetic resonance angiography at 3T study. Surg Radiol Anat 30(6):509-514, 2008

88. Wakabayashi Y, Hori Y, Kondoh Y, Asano T, Yamada A, Kenai $\mathrm{H}$, Yamashita M, Nagatomi H: Ruptured anterior cerebral artery aneurysm at the origin of the accessory middle cerebral artery. Neurol Med Chir (Tokyo) 51(9):645-648, 2011
89. Wollschlaeger G, Wollschlaeger PB, Lucas FV, Lopez VF: Experience and result with postmortem cerebral angiography performed as routine procedure of the autopsy. AJR Am J Roentgenol 101(1):68-87, 1967

90. Yamamoto $H$, Marubayashi T, Soejima T, Matsuoka $S$, Matsukado Y, Ushio Y: Accessory middle cerebral artery and duplication of middle cerebral artery- terminology, incidence, vascular etiology, and developmental significance. Neurol Med Chir (Tokyo) 32(5):262-267, 1992

91. Yanaka K, Shirai S, Shibata Y, Nose T: Ruptured aneurysm at the origin of the median artery of the corpus callosum associated with accessory middle cerebral artery. Neurol Med Chir (Tokyo) 40:511-514, 2000

92. Zurada A, Gielecki J, Tubbs RS, Loukas M, Cohen-Gadol AA, Chlebiej M, Maksymowicz W, Nowak D, Zawiliński J, Michalak M: Three-dimensional morphometry of the A2 segment of the anterior cerebral artery with neurosurgical relevance. Clin Anat 23(7):759-769, 2010 